\title{
Can Family Planning Programs Reduce High Desired Family Size in Sub-Saharan Africa?
}

During the past half century, fertility declines have been pervasive in Asia and Latin America. Between the early 1950s and the early 2000s, the total fertility rate (TFR)the average number of live births a woman would have during her lifetime, assuming constant fertility ratesdropped from 5.7 to 2.4 births per woman in Asia and from 5.9 to 2.3 births per woman in Latin America. ${ }^{1}$ Only a handful of countries in these regions still have fertility rates higher than four births per woman. In Sub-Saharan Africa, however, fertility remains high in the large majority of countries. Although some declines have occurred, the average total fertility rate in 2005-2010 exceeded 5.1 births per woman-more than double the levels observed in Asia and Latin America.

Several factors contribute to the high fertility rate in SubSaharan Africa. Compared with populations in Asia and Latin America, the continent's people are on average poorer, less educated and have higher child mortality. These factors contribute to a desire for large families, which in turn leads to high fertility. In addition, with few exceptions, governments in Sub-Saharan Africa have made family planning programs a low priority. ${ }^{2,3}$ Continued high fertility, combined with lower-than-expected mortality from the AIDS epidemic, are producing very rapid population growth. By 2050, Sub-Saharan Africa will have a billion more inhabitants than in 2005, according to the United Nations' medium projections. ${ }^{1}$

These trends pose a dilemma for policymakers. The first and most obvious step toward addressing high fertility is to implement family planning programs to provide women with contraceptive access and information. The level of unmet need for contraceptives is high throughout the region and large numbers of unintended pregnancies occur. $^{4-6}$ Preventing these pregnancies would benefit women, their families and society.

However, the high desired family size that prevails in much of Sub-Saharan Africa hampers fertility decline. Even if the existing unmet need for contraceptives could be addressed, fertility would remain well above replacement levels. This raises the question: Can fertility preferences be influenced, and if so, how? ${ }^{7}$ Reducing preferences has been a low priority throughout Asia and Latin America, where desired family size has declined to near replacement levels. But Sub-Saharan Africa is different. Although social and economic development may help reduce its high desired family size, the process could take decades; thus, massive population growth is inevitable.

The main objective of this study is to assess the poten- tial role of family planning services and media messages in changing fertility preferences. The existing evidence on this topic is inconclusive. A literature review by Freedman ${ }^{8}$ yielded mixed results: He found reduced preferences in some studies but not in others; moreover, most evaluations focused on the role of family planning in addressing unsatisfied contraceptive demand rather than on fertility preferences.

This study begins with a discussion of various measures of fertility preferences and then uses cross-country analyses to examine the potential role of family planning programs in reducing desired family size.

\section{Measures of Fertility Preferences}

Contemporary surveys such as the Demographic and Health Surveys (DHS) include several questions to assess women's childbearing preferences. ${ }^{9-14}$

-Ideal or desired family size. The DHS asks women, "If you could go back to the time [when] you did not have any children and could choose exactly the number of children to have in your whole life, how many would that be?" Estimates of average ideal or desired family size based on this type of question are widely used, partly because they are easy to interpret. However, there are two potential sources of bias: nonresponse and rationalization. In the 1970s, more than $25 \%$ of women in some countries gave a nonnumeric response (e.g., up to God), but nonnumeric responses have declined over time, constituting fewer than $5 \%$ of responses in a majority of DHS surveys. The stated ideal number of children also can reflect a woman's reluctance to provide an ideal family size that is smaller than her current number of living children. Such rationalization is most common among older women with many living children.

- Wanted fertility. The standard DHS procedure for estimating the wanted total fertility rate (using the wanted status of births) divides the number of observed births into those that occur before and after the desired family size is reached; the former are considered wanted (even though some may be mistimed), the latter unwanted. The wanted total fertility rate is obtained with the same standard procedure used to calculate the overall total fertility rate from age-specific fertility rates; however, only wanted births are included in the numerators of these rates. The wanted total fertility rate is useful because it estimates the fertility that would be observed if all unwanted childbearing were eliminated. However, the wanted total fertility rate is problematic as an indicator of preferences for several reasons.
By John Bongaarts

John Bongaarts is vice president and distinguished scholar, Population Council, New York. 
First, it is derived from the desired family size, so it incorporates any accompanying biases. Second, the wanted total fertility rate can substantially deviate from the desired family size for multiple reasons that are unrelated to preferences. For example, wanted total fertility will fall short of desired family size if a significant proportion of women never marry or become infecund before reaching their desired fertility. Alternatively, the wanted total fertility rate can exceed the desired family size when women replace children who have died with additional births to reach the desired number of surviving children.

-Wanted status of recent births. In principle, the simplest way to estimate wanted fertility is to ask women whether recent births were wanted. For example, the DHS asks women, for each of their births in the last five years, "Just before you became pregnant with _ , did you want to have more children then, did you want to wait longer or did you want no more children?" The problem with this approach is that women are reluctant to admit that a child (who is likely living with them) was not wanted. The DHS does not use this information to calculate wanted fertility rates because it is assumed that this approach provides an overestimate of wanted fertility.

- Desire for more children. Asking women whether they want more children is straightforward and there is no obvious reason why their answers would be biased. However, the information collected presents two problems. First, there is no simple way to turn estimates of the proportion of women wanting more children by age or parity into a life cycle estimate that can be compared with the desired family size or wanted total fertility rate. ${ }^{10,11}$ Second, the proportion of women wanting more children is affected by factors other than family size preferences. In particular, for a given desired family size, a population with wide birth spacing will have a higher proportion of women wanting

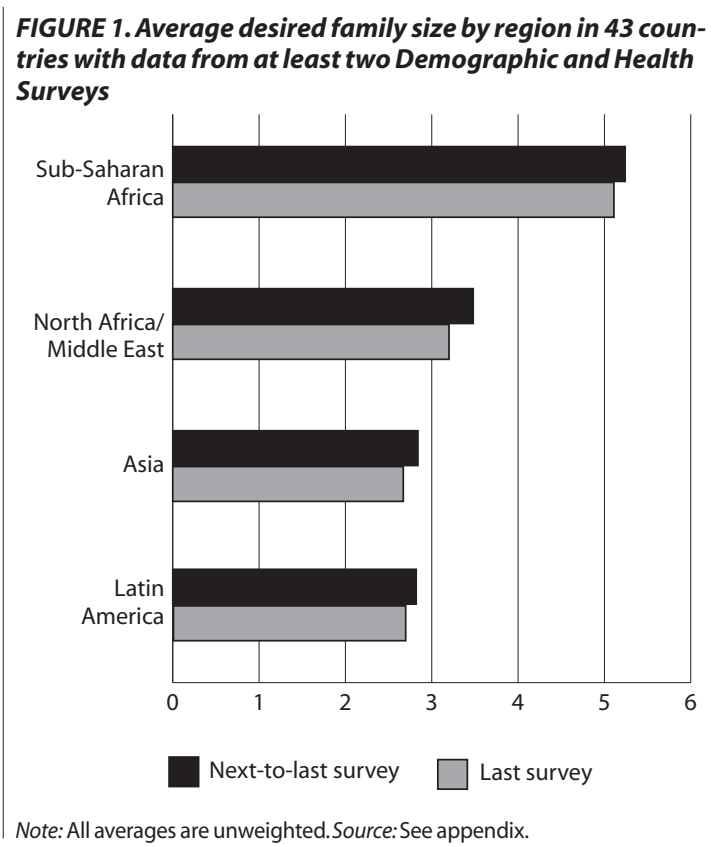

more children than a population with the same desired family size and short birth intervals.

In sum, all of these options for estimating fertility preferences have some drawbacks. In the analysis that follows, the desired family size will be the primary indicator used because it is least problematic for present purposes. To minimize bias due to rationalization and nonresponse, the average estimate of desired family size will be based on women aged 20-35.

\section{Levels and Trends in Desired Family Size}

Estimates of trends in desired family size are available for 43 countries in Sub-Saharan and North Africa, the Middle East, Asia and Latin America in which two or more DHS surveys have been conducted (see appendix).

Figure 1 presents trends in the unweighted average desired family size in each region. The values shown in the figure were calculated by averaging the desired family sizes for all countries within each region at two points-each country's last DHS survey and its next-to-last survey. The average years for these two surveys were 2005 and 1999 , respectively (see appendix).

At the time of the last survey, the average desired family size for Sub-Saharan Africa (5.1 children per woman) was higher than the averages for North Africa and the Middle East (3.2), Asia (2.7) and Latin America (2.7). Decreases in these averages were modest. In particular, the decline in the Sub-Saharan African countries averaged just 0.13 children per woman. At this slow pace, it will take more than a century to reach a desired family size of two children.

To provide a longer-range perspective, we examined trends in desired family size for 10 countries (Senegal, Ghana, Kenya, Egypt, Jordan, Bangladesh, Indonesia, Colombia, the Dominican Republic and Peru) for which five successive surveys are available (see Web appendix). The first survey for each country, a World Fertility Survey, took place in the late 1970s. The remaining four (DHS surveys) took place in 1990, 1995, 2000 and 2005. Decreases in desired family size were fairly steep before the 1990s, but have slowed or stalled since the mid-1990s. One would expect the pace of decline in desired family size to slow as countries approach the end of the fertility transition, but the nearly stalled decline in countries in midtransition-Senegal, Ghana, Kenya and Jordan-is a surprise.

For obvious reasons, trends in family size preferences have important implications for trends in fertility. A full discussion of the complex relationship between desired family size and the total fertility rate is beyond the scope of this paper, but a few points should be noted. With the nearly constant and high desired number of children in Sub-Saharan Africa, one would expect the total fertility rate to be high and fairly stable. An analysis of fertility trends in Sub-Saharan Africa confirmed this, and concluded that more than half of the countries in the region had not experienced a significant decline in fertility between the most 
recently available surveys. ${ }^{15}$ Although a reduction of unwanted fertility could reduce the total fertility rate significantly, the fertility transition in this region cannot proceed to replacement level unless large declines in desired family size occur. The high and nearly stable desired family size is therefore an obstacle to further fertility decline. In other regions of the developing world, family size preferences are much lower, but the pace of fertility declines has also slowed over time, suggesting that further reductions in the total fertility rate will occur at a modest pace.

\section{Determinants of Desired Family Size}

Conventional demographic theory holds that socioeconomic development reduces desired family size during the transition from traditional agricultural to modern industrial society. ${ }^{16-17}$ As countries develop, the theory posits, the cost of having children rises and the benefits wane, leading parents to want fewer children. In addition, declines in child mortality reduce the number of births needed to achieve a given family size, as well as the uncertainty surrounding child survival; thus, parents can plan their families with more confidence.

It is therefore not surprising that family size preferences are negatively correlated with standard measures of socioeconomic development. For example, for the 62 DHS countries with at least one survey, the correlation between desired family size and the percentage of women schooled $(p<0.000)$, the percentage of children surviving to age 5 $(p<0.000)$ and gross domestic product (GDP) per capita in constant U.S. dollars ( $\mathrm{p}<0.000)$ is inverse and highly significant.

Unfortunately, multicollinearity precludes drawing conclusions about causality from these results. Further insight can be gained with a multivariate regression in which desired family size is the dependent variable and the three development indicators are the explanatory factors (Table 1). A dummy variable for countries in Sub-Saharan Africa is included. All variables are estimated from the DHS except GPD per capita, which comes from Heston et al. ${ }^{18}$

The effects of the socioeconomic indicators are in the expected direction, i.e., more schooling, higher survival and higher incomes are associated with lower desired family size. The schooling and survival effects are statistically significant, but the effect of GDP per capita is not significant and the coefficient is very small. This finding suggests

\begin{tabular}{|c|c|}
\hline Variable & Effect (SE) \\
\hline Women schooled (\%) & $-0.018(0.006)^{* *}$ \\
\hline Child survival (\% at age 5 ) & $-0.085(0.039)^{*}$ \\
\hline GDP per capita (log, constant US\$) & $-0.126(0.479)$ \\
\hline Sub-Saharan Africa & $1.094(0.292)^{* *}$ \\
\hline Intercept & $12.71(3.227)^{* *}$ \\
\hline$R^{2}$ & 0.706 \\
\hline
\end{tabular}

that poor countries can reach low desired family size by raising education and survival levels. For example, Sri Lanka and the Indian state of Kerala have followed this development path.

The large and highly significant dummy variable for Sub-Saharan Africa indicates that desired family size in this region is on average 1.1 children higher than elsewhere in the developing world after accounting for the effects of socioeconomic variables. This result is expected from earlier research, which has demonstrated that African societies are particularly pronatalist. ${ }^{19}$

These findings are largely consistent with the conventional wisdom on the determinants of desired family size. But there is more to the story, as this Comment will demonstrate.

\section{Family Planning Programs and Desired Family Size}

Family planning programs give women contraceptive information and access. Many developing countries have implemented such programs to reduce high birthrates, lower maternal and infant mortality and support women's right to decide how many children to have. The primary justification for voluntary family planning programs is substantial unmet need for contraception, which was first documented in the 1960s. This unmet need results in 76 million unplanned pregnancies each year, about half of which end in abortion, and the other half in births. ${ }^{5}$ The effectiveness of these programs has been demonstrated in controlled experiments, such as the one conducted in the Matlab district of rural Bangladesh starting in the late 1970s. ${ }^{20}$

Family planning programs vary widely in the coverage and quality of their services. In some countries, services are minimal, and funding and political commitment are lacking; in other countries, services are comprehensive, providers well trained, and funding and political commitment strong. Unfortunately, the measurement of a country's family planning program effort is not straightforward. In particular, gathering information about family planning programs from individual women in surveys such as the DHS is not useful. Women can answer questions about their contraceptive practice and supply sources, but such information will not yield a complete and unbiased picture of the supply environment. A better approach would be to gather information directly by interviewing and observing providers who supply contraceptives. However, such surveys of the service environment would be costly and therefore are not feasible for most developing countries.

An alternative approach to measuring family planning program effort was proposed in the early 1970s, when interest in monitoring these programs first developed. ${ }^{21,22}$ This approach identifies a few knowledgeable observers in each country and questions them on about 125 items dealing with a variety of program characteristics. Answers to these questions are combined to yield an overall family planning program effort score, which is usually expressed as a percentage of the maximum possible score (in 1999, the highest score was $82 \%$ for Indonesia and the lowest 
was 35\% in Congo). During the past three decades, assessments of this type have been conducted every five years. The present analysis used results from the 1999 cycle because it preceded the large majority of the DHS surveys from which the fertility measures were taken but is close enough to the most recent surveys to be relevant.

An advantage of the expert-respondent method is its relatively low cost, which is essential for collecting information in a large number of countries. But there are disadvantages as well. In some countries, only two or three experts provide input, the accuracy and objectivity of which are not clear. In addition, experts consulted in successive rounds are often not the same individuals. As a result, program effort estimates may contain errors and biases of unknown magnitude. Nevertheless, studies have assessed the validity and reliability of this index and generally found it to be useful. ${ }^{22}$

Family planning programs (as measured by the family planning program effort score) have been shown to have an impact on fertility or contraceptive use after controlling for socioeconomic variables. ${ }^{22-24}$ Here, we conduct the same type of analysis, but use desired family size rather than fertility or contraceptive use as the dependent variable.

In a second ordinary least squares regression analysis, we add the program effort score as an explanatory variable (Table 2). The effects of the socioeconomic variables and the dummy for Sub-Saharan Africa are not significantly different from those estimated earlier. The main finding is that program effort has a strong and highly significant effect on desired family size.

\section{Case Studies}

We now compare the experiences and program effort scores of four pairs of countries-Bangladesh and Pakistan, Iran and Jordan, Kenya and Uganda, and Indonesia and the Philippines-to further demonstrate the potential impact of family planning programs on fertility preferences. The level of development (as measured by the Human Development Index) for the two countries within each pair is similar. $^{25}$

Strong, well-funded programs that provide subsidized contraceptive services nationwide have been implement-

\begin{tabular}{|c|c|}
\hline Variable & Effect (SE) \\
\hline Women schooled (\%) & $-0.018(0.006) * *$ \\
\hline Child survival (\% at age 5 ) & $-0.077(0.037) *$ \\
\hline GDP per capita (log, constant \$) & $0.011(0.433)$ \\
\hline Sub-Saharan Africa & $1.028(0.283) * *$ \\
\hline Family planning effort score (\%) & $-0.039(0.012)^{* *}$ \\
\hline Intercept & $13.66(2.959) * *$ \\
\hline$R^{2}$ & 0.768 \\
\hline $\mathrm{N}$ & 50 \\
\hline
\end{tabular}

ed by the governments of Bangladesh (program effort score, $74 \%$ of maximum), Kenya (62\%), ${ }^{*}$ Iran (71\%) and Indonesia (82\%); in addition, vigorous information, education and communication campaigns communicate the benefits of contraception and small families. In contrast, relatively weak family planning programs that lack funding and political commitment exist in Pakistan (57\%), Jordan (47\%), Uganda (54\%) and the Philippines (54\%).

Thus, the countries in each pair have similar social, economic and cultural characteristics, but only one country in each pair has implemented a strong family planning program. These pairings therefore represent natural experiments to assess how family planning programs may influence reproductive behavior.

We present several indicators of fertility and fertility preferences for each of the pairs of countries (Figures 2-5). The results are in the expected direction in all comparisons and in all four pairs. Although fertility itself is not the focus of this study, it provides a useful reference point. The total fertility rates in countries with weak programs exceed those of countries with strong programs by a significant margin, with an average difference of 1.4 births per woman (Figure 2). The difference in the countries' total fertility rates stems from a combination of lower wanted fertility and lower unwanted fertility in the countries with strong programs (Figures 3 and 4, page 214). Finally, the average desired family size is 2.8 in the countries with strong programs and 4.1 in the countries with weak programs (Figure 5, page 214). The difference in desired family size is largest for the Jordan-Iran and the Pakistan-Bangladesh pairs. The difference is smallest for the PhilippinesIndonesia pair.

Another informative comparison is between Rwanda and Burundi, two poor, densely populated countries in East Africa (not shown). Until 2000, both countries had fertility levels of more than six children per woman and weak family planning programs. But in the mid 2000s, the Rwandan government renewed its lagging commitment to family planning and, with strong support from international donors, it sharply increased access to contraceptive methods throughout the country. ${ }^{26,27}$ Government officials had spoken out about the need to reduce fertility, and a countrywide information, education and communication program was implemented. As a result, reproductive behavior changed quickly: Between DHS surveys in 2005 and 2010, Rwanda's total fertility rate dropped from 6.1 to 4.6, and modern contraceptive use among married women rose from $10 \%$ to $45 \% .{ }^{28}$ In addition, the proportion of women wanting no more children rose from $42 \%$ to $52 \%$.

By comparison, fertility in Burundi changed little and was still high-6.4 births per woman-in 2010. ${ }^{29}$ Unfortunately, preliminary reports from the 2010 surveys in these two countries do not provide estimates of desired family size or wanted fertility. However, the Rwandan experience

*Kenya's program has deteriorated in the past decade. 
strongly suggests that other poor countries in Africa can achieve similar rapid change in reproductive behavior if they invest in family planning programs.

Results from these case studies support the conclusion that family planning programs affect desired family size. Because it is impossible to rule out a role for unobserved confounding factors, however, results from such natural experiments are inconclusive.

\section{A Puzzle: The Matlab Experiment}

One of the best known and most influential controlled family planning experiments began in 1977 in the Matlab district of Bangladesh. Matlab's population of 173,000 was divided into roughly equal experimental and control areas. In the experimental half, the quality of family planning services (including home visits, access to an array of methods and follow-up care) was greatly improved. In the control half, no changes were made in the standard services provided by the national program. Improved services provided large and immediate results: ${ }^{20}$ Contraceptive use in the experimental area jumped from 5\% to 33\% in the first 18 months and remained 25\% higher than in the control area until the 1990s, when service improvements in the control area (and nationwide) narrowed the gap. Thus, fertility declined in the experimental area, and the difference between the areas of 1.5 births per woman was maintained until approximately 20 years ago. The Matlab experiment demonstrated that family planning programs can succeed even in very traditional societies. The success of this intervention led the Bangladesh government to apply the lessons of the experiment to its national program.

To understand the factors that drove this fertility decline, Koenig et al. ${ }^{30}$ examined the trend in preferences during the first seven years of the experiment (1977-1984). Unfortunately, this assessment was hampered by a lack of consistent measures of fertility preferences over time. Nevertheless, the authors concluded that family size preference in Matlab had declined by 1984, but that the decline had been no larger in the experimental than in the control area. This finding implies that the observed uptake in contraceptive use and the corresponding decline in fertility in the intervention area resulted mostly from a rise in fulfillment of latent or unsatisfied demand for contraceptives. ${ }^{8,30}$

How can this result from the Matlab experiment be reconciled with earlier evidence of family planning programs' impact on family size preferences? The answer to this puzzle appears to be the information, education and communication program that has been implemented throughout Bangladesh since the 1970s. The program's emphasis on the benefits of smaller families and contraception most likely reached and affected the control and intervention areas equally. This media effort has been extensive and involves political and religious leaders. As Khuda and colleagues $^{31}$ have noted, Radio Bangladesh has assigned more than 90 minutes a day of its national and regional programming to population and family planning issues, while television has allocated two hours a week. Moreover,
FIGURE 2. Total fertility rate for pairs of countries

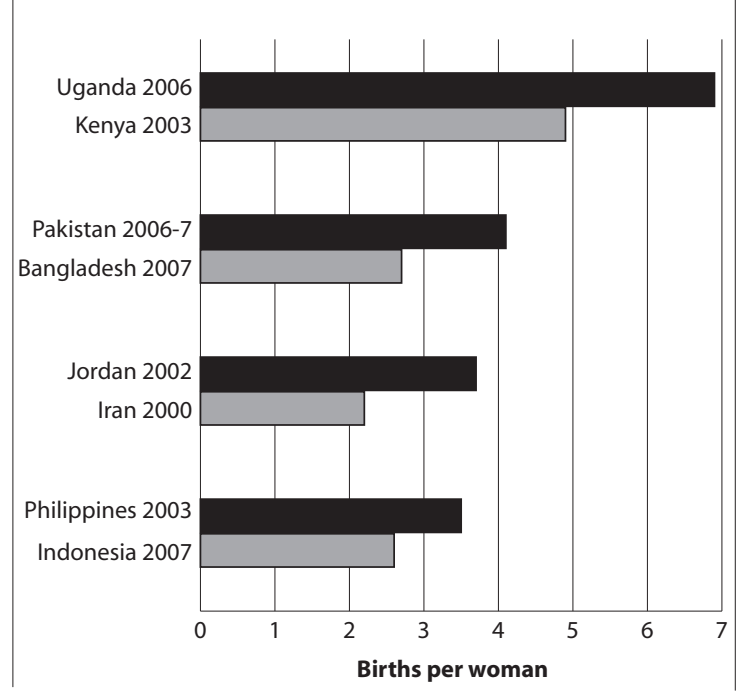

the Information, Education and Motivation Unit of the Directorate of Family Planning has provided information courses for leaders at all levels, including imams, who have received honoraria for promoting family planning at the Friday mosque

These efforts likely contributed to the decline of desired family size in Bangladesh, from 4.1 in mid-1975 to 2.8 in early 1993. Modest improvements in development indicators also may have contributed to declining fertility preferences, even though Bangladesh in 1993 was still one of the world's poorest and least developed countries.

\section{Possible Mechanisms}

Family planning programs' impact on fertility generally is attributed to their meeting an existing demand for contraceptives: ${ }^{3-5,32-35}$ Reducing the costs of contraception (monetary, travel, social) can satisfy unmet need, increase contraceptive use and reduce fertility. But this study examines another plausible pathway: the reduction of de-

FIGURE 3. Wanted total ferility rate for pairs of countries

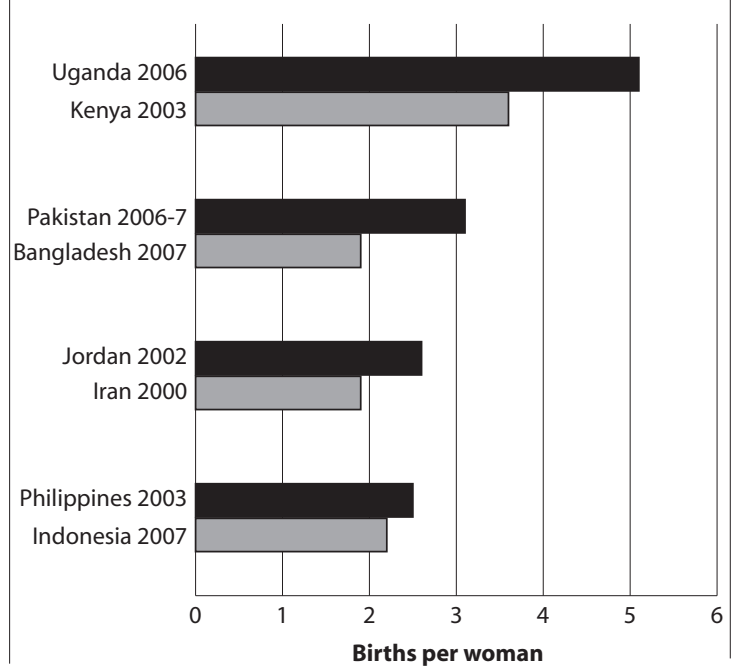


FIGURE 4. Unwanted total fertility rate for pairs of countries

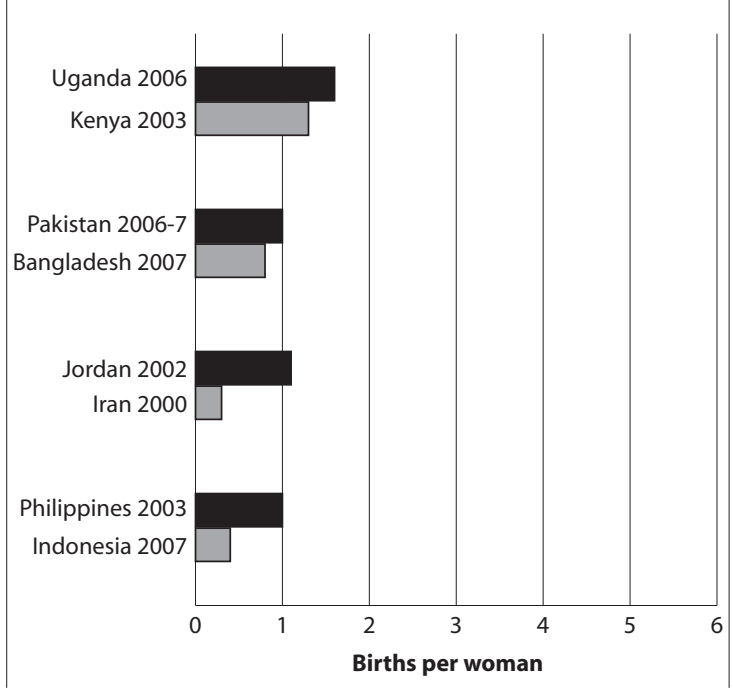

sired family size. The very limited literature on this subject has yielded two hypotheses about the underlying mechanism for such a link.

- The costs of contraception affect preferences. According to Easterlin's ${ }^{33,34}$ widely used framework for the determinants of fertility, the demand for children and the costs of contraception both affect fertility, albeit independently. The former is determined by social and economic factors as well as child mortality; the latter is affected by a range of factors (e.g., lack of knowledge, costs of travel, contraceptive commodities and providers, objections from husbands or family, fear of side effects). Robinson and Cleland ${ }^{7}$ have examined this issue and concluded that the assumption of independence is questionable. They argue that when the overall costs (including social, economic and health) of regulating fertility are high, the demand for fertility limitation is weak, because there is little point in aiming for a goal that cannot be implemented without great difficulty (e.g., by abstinence). In contrast, reduced

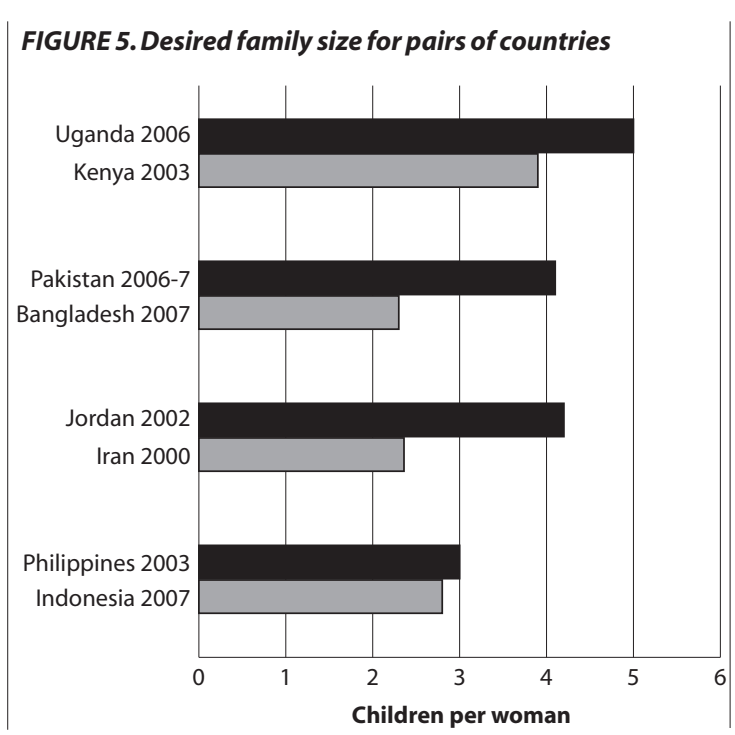

costs allow couples to reassess, reaffirm and more readily attain their fertility preferences. Although this conclusion seems reasonable and plausible, Robinson and Cleland have not provided direct empirical evidence to support their claim.

- Information education and communication programs. Family planning programs generally use education and communication programs to provide women with information about birth control methods and where and how to obtain them. This information increases the social acceptability of birth control and counters unfounded rumors and negative perceptions of methods. Information, education and communication programs also explain the advantages of small families. Their messages, especially on radio and television, appear to have had a substantial impact on fertility preferences. ${ }^{3,36-39}$ This impact seems to have been increased by strong and visible government support, as the previous case studies have illustrated.

Unfortunately, available survey data do not allow the accurate estimation of the contribution these mechanisms have made to declines in family size preferences in many countries

\section{Conclusion}

In the past 50 years, a reproductive revolution has swept through much of the developing world, leading to large fertility declines in Asia, Latin America and North Africa. In contrast, fertility declines in Sub-Saharan Africa have been small on average, and the continent's total fertility has remained higher than five births per woman. Hence, its population has more than quadrupled between 1950 and 2010 and is expected to double again by 2050. These demographic trends in Sub-Saharan Africa have raised concerns about their potential adverse impact on health, social and economic development and the environment. ${ }^{40}$

Such concerns have led to investments in family planning programs, especially in Asia, Latin America and North Africa, where levels of unwanted and unplanned childbearing, and an unsatisfied demand for contraceptives have been well documented. Family planning programs allow women and men to control their reproductive lives, thus improving their family's welfare and benefiting their country's economy and environment. International consensus on this issue is reflected in the UN Millennium Development Goals, specifically Target 5.B-to provide universal access to reproductive health by 2015 and to reduce the unmet need for family planning.

Despite the well-recognized benefits of family planning programs, policymakers in Sub-Saharan Africa have made limited investments in them; one key reason is the AIDS epidemic, which has caused many deaths. However, early predictions of the decline of Africa's population ${ }^{41}$ have not been realized; the epidemic has peaked and its demographic impact has been limited, partly because of widely available antiretroviral treatment.

A second reason for limited investments in family planning is the belief that it cannot succeed given Africa's cul- 
tural bias toward large families. ${ }^{19}$ However, this obstacle is partly surmountable. Survey data show a pervasive unmet need for birth spacing and limiting in African countries. 5,6 Although contraceptive demand is lower in Africa than in Latin America and Asia, it remains substantial and unsatisfied. Even if all unmet need could be met, fertility would remain well above replacement because the desired family size is almost five children.

This leaves the key question: Can family planning programs reduce desired family size? The evidence strongly suggests that the answer is yes. Both cross-national analyses and case studies support the argument that family planning programs can indeed change reproductive preferences.

\section{REFERENCES}

1. United Nations, World Population Prospects: The 2008 Revision, New York: United Nations, 2009

2. Blanc AK and Tsui AO, The dilemma of past success: insiders' views on the future of the international family planning movement, Studies in Family Planning, 2005, 36(4):263-276.

3. Cleland J et al., Family planning: the unfinished agenda, Lancet, 2006, 368(9549): 1810-1827.

4. Casterline J and Sinding S, Unmet need for family planning in developing countries and implications for population policy, Population and Development Review, 2000, 26(4):691-723.

5. Singh S et al., Adding It Up: The Costs and Benefits of Investing in Family Planning and Maternal and Newborn Health, New York: Guttmacher Institute and United Nations Population Fund, 2009.

6. Westoff CF, Unmet need at the end of the century, DHS Comparative Reports, Calverton, MD, USA: ORC Macro, 2001, No. 1.

7. Robinson W and Cleland J, The influence of contraceptive costs on the demand for children, in: Phillips JF and Ross JA, eds., Family Planning Programmes and Fertility, New York: Oxford University Press, 1992, pp. $106-122$

8. Freedman R, Do family planning programs affect fertility preferences? A literature review, Studies in Family Planning, 1997, 28(1):1-13.

9. Bankole A and Westoff C, Childbearing attitudes and intentions, DHS Comparative Studies, Calverton, MD, USA: Macro International, 1995, No. 17.

10. Bongaarts J, The measurement of wanted fertility, Population and Development Review, 1990, 16(3):487-506.

11. Casterline J and El-Zeini LO, The estimation of unwanted fertility, Demography, 2007, 44(4):729-745.

12. Lightbourne R, Individual preferences and fertility behavior, in: Cleland J and Hobcraft J, eds., Reproductive Change in Developing Countries: Insights from the World Fertility Survey, Oxford: Oxford University Press, 1985, pp.165-198.

13. Lightbourne R, Reproductive preferences and behavior, in: Cleland J and Scott C, eds., The World Fertility Survey, Oxford: Oxford University Press, 1987, pp. 838-861.

14. Westoff CF, Desired number of children: 2000-2008, DHS Comparative Reports, Calverton, MD, USA: ICF Macro, 2010, No. 25.

15. Bongaarts J, Fertility transitions in the developing world: progress or stagnation? Studies in Family Planning, 2008, 39(2):105-110.

16. Notestein F, Population-the long view, in: Schultz TW, ed., Food for the World, Chicago: Chicago University Press, 1945.

17. Notestein F, Economic problems of population change, in: Proceedings of the Eighth International Conference of Agricultural Economists, London: Oxford University Press, 1953, pp. 13-31.

18. Heston A, Summers R and Aten B, Penn World Table Version 6.3, Philadelphia: Center for International Comparisons of Production,
Income and Prices at the University of Pennsylvania, 2009 $<$ http://pwt.econ.upenn.edu/php_site/pwt_index.php>, accessed Aug. $15,2011$.

19. Caldwell J and Caldwell $P$, Is the Asian family planning model suited to Africa? Studies in Family Planning, 1988, 19(1):19-28.

20. Cleland J et al., The Determinants of Reproductive Change in Bangladesh: Success in a Challenging Environment, Washington, DC: World Bank, 1994

21. Lapham R and Mauldin P, National family planning programs: review and evaluation, Studies in Family Planning, 1972, 3(3):29-52.

22. Ross J and Stover J, The family planning program effort index: 1999 cycle, International Family Planning Perspectives, 2001, 27(3):119-129.

23. Bongaarts J, The role of family planning programmes in contemporary fertility transitions, in: Jones GW et al., eds., The Continuing Demographic Transition, Oxford: Oxford University Press, 1997, pp. 422444

24. Freedman R and Berelson B, The record of family planning programs, Studies in Family Planning, 1976, 7(1):1-40.

25. United Nations Development Program (UNDP), Human Development Report 2009, New York: UNDP, 2009, <http://hdrstats.undp.org/en/ indicators/74.html >, accessed Aug. 15, 2011

26. Solo J, Family Planning in Rwanda. How a Taboo Topic Became Priority Number One, Chapel Hill, NC, USA: IntraHealth International, 2008.

27. United States Agency for International Development, Rwanda: Family Planning Briefer, 2009, <http://www.usaid.gov/rw/our_work/ programs/familyplaning.html>, accessed Aug. 15, 2011.

28. National Institute of Statistics of Rwanda, Rwanda Demographic and Health Survey 2010, Preliminary Report, Calverton, MD, USA: Measure DHS and ICF Macro, 2011

29. Institut de Statistiques et d'Études Économiques du Burundi, Enquête Démographique et de Santé Burundi 2010, Rapport Préliminaire, Calverton, MD, USA: Measure DHS and ICF Macro, 2010

30. Koenig $\mathrm{M}$ et al., Trends in family size preferences and contraceptive use in Matlab, Bangladesh, Studies in Family Planning, 1987, 18(3):117127.

31. Khuda B et al., Determinants of fertility transition in Bangladesh, in: Sathar Z and Philips J, eds., Fertility Transition in South Asia, Oxford: Oxford University Press, 2001, pp. 364-385.

32. Bongaarts J, Fertility transitions in the developing world: progress or stagnation? Studies in Family Planning, 2008, 39(2):105-110.

33. Easterlin RA, An economic framework for fertility analysis, Studies in Family Planning, 1975, 6(3):54-63.

34. Easterlin RA, The economics and sociology of fertility: a synthesis, in: Tilly C, ed., Historical Studies of Changing Fertility, Princeton, NJ, USA: Princeton University, 1978, pp. 57-113.

35. Pritchett L, Desired fertility and the impact of population policies, Population and Development Review, 1994, 20(1):1-55.

36. Hornik R and McAnany E, Mass media and fertility change, in: Casterline J, ed., Diffusion Processes and Fertility Transition: Selected Perspectives, Washington, DC: National Academy Press, 2001, pp. 208-239.

37. Westoff C, Mass communications and fertility, in: Leete R, ed. Dynamics of Values in Fertility Change, Oxford: Oxford University Press, 1999, pp. 237-251.

38. Westoff CF and Bankole A, Mass media and reproductive behavior in Africa, Demographic and Health Surveys Analytical Reports, Calverton, MD USA: Macro International, 1997, No. 2.

39. Westoff CF and Rodriguez G, The mass media and family planning in Kenya, International Family Planning Perspectives, 1995, 21(1):26-31 \& 36.

40. May JF, World Population Policies: Their Origin, Evolution and Impact, New York: Springer-Verlag, 2012.

41. Garnett GP and Anderson RM, No reason for complacency about the potential demographic impact of AIDS in Africa, Transactions of the Royal Society of Tropical Medicine and Hygiene, 1993, 87(1 Suppl.):S19-S22. 


\section{Appendix}

Estimates of trends in desired family size are available for the following 43 countries in which two or more DHS surveys have been conducted (dates of last two surveys in parentheses):

- Sub-Saharan Africa. Benin (2001, 2006), Burkina Faso (1998-1999, 2003), Cameroon (1998, 2004), Chad (1996-1997, 2004), Cote d'Ivoire (1994, 1998-1999), Ethiopia (2000, 2005), Ghana (2003, 2008), Guinea (1999, 2005), Kenya (2003, 2008-2009), Madagascar (2003-2004, 2008-2009), Malawi (2000, 2004), Mali (2001, 2006), Mozambique (1997, 2003), Namibia (2000, 2006-2007), Niger (1998, 2006), Nigeria (2003, 2008), Rwanda (2005, 2007-2008), Senegal (1997, 2005), Tanzania (1999, 2004-2005), Uganda (2000-2001, 2006), Zambia (2001-2002, 2007), Zimbabwe (1999, 20052006).

- North Africa/Middle East. Egypt (2005, 2008), Jordan (2002, 2007), Morocco (1992, 2003-2004), Turkey (1993, 1998), Yemen (1991-1992, 1997).

-Asia. Bangladesh (2004, 2007), Cambodia (2000, 2005), India (1998-1999, 2005-2006), Indonesia (2002-2003, 2007), Nepal (2001, 2006), Pakistan (1990-1991, 2006-2007), Philippines (2003, 2008), Vietnam (1997, 2002).

-Latin America. Bolivia (1998, 2003), Colombia (2000, 2005), Dominican Republic (2002, 2007), Guatemala (1998-1999, 2002), Haiti (2000, 2005-2006), Nicaragua (1998, 2001), Paraguay (1990, 2004), Peru (1996, 2000).

\section{Acknowledgement}

This research was funded through a grant from the William and Flora Hewlett Foundation.

Author contact:Jbongaarts@popcouncil.org 